\title{
A COMPARATIVE STUDY BETWEEN POROUS TITANIUM GRANULES AND NANOCRYSTALLINE HYDROXYAPATITE IN HEALING OF MANDIBULAR DEFECTS IN DOGS
}

\author{
Ahmed $\mathrm{N}^{1} B D S$, Mahmoud $\mathrm{T}^{2} P h D$, Shafik $\mathrm{S}^{3} P h D$, El Dibany $\mathrm{R}^{2} P h D$.
}

\begin{abstract}
: hydroxyapatite. estimated by histological and histomorphometric analysis. Nanobone ${ }^{\circledR}$ at 3, 6 and 12 weeks intervals post-operatively. the mean bone volume value between the two groups. group; bone was formed within its porosities

Key Words: Porous Titanium Granules, Nanobone®, bone defects, bone volume, histomorphometric analysis.

1- Dentist, Faculty of Dentistry, Alexandria University, Egypt

2- Professor of Oral and Maxillofacial Surgery, Faculty of Dentistry, Alexandria University, Egypt.

3- Professor of Oral Biology, Faculty of Dentistry, Alexandria University, Egypt.
\end{abstract}

Background: Bone grafting is a common technique in Oral and Maxillofacial surgery to replace missing bone. Grafting materials include autografts, allografts, xenografts and synthetic bone substitutes. Two synthetic bone materials are currently available; porous titanium granules and nanocrystalline

Objectives: This study compared the use of Porous titanium granules (PTG) versus Nanobone ${ }^{\circledR}$ in healing of mandibular defects in dogs and this was

Materials and Methods: The study was conducted on 10 healthy experimental dogs. An osseous defect of $10 \mathrm{~mm}$ depth and $10 \mathrm{~mm}$ width was created in the premolar area of both right and left sides of the mandible. The right side defects were grafted with PTG while the left side defects were grafted with Nanobone ${ }^{\circledR}$. Histological and histomorphometrical evaluation was carried out to monitor bone healing and quantify the bone volume with both PTG and

Results: The mean bone volume value with PTG was $773.4 \pm 499.4$ on the 3 rd week, then increased on the 6 th week to be $10125.3 \pm 19287.3$ and $2676.0 \pm 1388.2$ on the 12 th week. The mean bone volume value with Nanobone ${ }^{\circledR}$ was $525.5 \pm 332.1$ on the $3 \mathrm{rd}$ week, then on the 6 th week it became $287.4 \pm 322.5$. There was a statistically significant increase on the 12 th to be $1976.8 \pm 1568.1$. There was a statistically significant difference regarding

Conclusion: Both PTG and Nanobone ${ }^{\circledR}$ have osteoconductive properties and are effective in healing bone defects, but the histomorphometric analysis quantified the bone volume with both PTG and Nanobone ${ }^{\circledR}$ and revealed that the maximum amount of the total regenerated bone was seen in the PTG

\section{INTRODUCTION}

Bony defects in the jaw occur for various reasons. They are caused by infection, tumors or cysts. To maintain teeth or to provide sufficient bone height for later implantation or prosthesis supply, the filling of bone defect is necessary (1).

Grafting materials include autografts, allografts, xenografts and synthetic bone substitutes. However, the majority of grafting procedures are autografts. i.e. the graft is taken from the same patient. The graft can be harvested either intraorally; from the mandibular symphysis, retromolar region or maxillary tuberosity or extraorally; from the femur, tibia, ribs or iliac crest of the pelvis $(2,3)$.

Nanocrystalline hydroxyapatite bone graft has been introduced for augmentation procedures in intrabony defects. Its Advantages are osteoconductivity and bioresorbablity (4). When it is used as a bone graft substitute, rapid healing of critical size defects was observed in animal experiments and in human applications (4). It binds to bone and stimulates bone healing by stimulation of osteoblastic activity (5).

Nanobone ${ }^{\circledR}$ is a nanocrystalline hydroxyapatite embedded in a porous silica gel matrix. Unlike conventional $\mathrm{HA}$ forms that are usually sintered at temperatures ranging from $700^{\circ} \mathrm{C}$ up to $1200^{\circ} \mathrm{C}$, Nanobone ${ }^{\circledR}$ is produced at a temperature $<200^{\circ} \mathrm{C}$. The lower processing temperature has a profound effect on the material's porosity and surface area (6).
The biocompatibility of titanium (Ti) has been proved in recent years. Titanium particles can stimulate the activation of complement system and platelets and can increase the level of platelet-derived growth factor. This factor has been shown to promote bone growth (7). These properties of titanium are incorporated in porous titanium granules (PTG), which contain 700-1000 micrometers diameter granules, and its porous nature makes the bone infiltration through the particles possible (8-13).

Therefore, due to the scarce histological data on both PTG and Nanobone ${ }^{\circledR}$ this study was designed to compare histologically and histomorphometrically the osseous defect regeneration and bone volume value after applying PTG and Nanobone ${ }^{\circledR}$.

\section{MATERIALS AND METHODS}

This study was conducted on 10 healthy adult mongrel dogs, about 18-24 months old, and with an average weight 10 to $15 \mathrm{~kg}$. The animals were kept under the same nutritional and environmental conditions at the Physiology Department, Faculty of Medicine, Alexandria University. The dogs were divided equally into two groups (right side and left side);

Group I: A surgical defect was created in the right premolar area of the body of the mandible and was grafted with PTG (Natix $\left.{ }^{\mathrm{TM}}\right)$. 
Group II: A surgical defect was created in the left premolar area of the body of the mandible and was grafted with Nanobone®.

Natix ${ }^{\text {TM }}$ PTG (Tigran technologies AB: Medeon science park, S-205 12 Malano, Sweden) is a bone graft material made of pure titanium and available in vials. The titanium granules are between $0.7 \mathrm{~mm}$ and $1.0 \mathrm{~mm}$ in size, porous, irregular in shape, grey in color and non-resorbable. These irregularities enable the granules to interlock with bone thus enabling primary and long term stability through osteoconduction and osseointegration.

Nanobone ${ }^{\circledR}$ (Nanograft: Pharma k dental Gmbh, Germany) consists of nanocrystalline HA embedded in a silica gel matrix. It has two forms; fine $(0.6 \mathrm{~mm} \times 2 \mathrm{~mm})$ and rough $(1 \mathrm{~mm} \times 2 \mathrm{~mm})$. All NanoBone ${ }^{\circledR}$ technology products are produced in a sol-gel process at temperatures below $200^{\circ} \mathrm{C}$. The low temperatures means that the material is not sintered and its surface is therefore highly porous with pores ranging from nanometers to micrometers in size. The autologous proteins from the blood enter the nanopores and cover the entire inner surface.

All dogs were healthy as documented by a veterinarian report. All dogs were kept on the same balanced diet consisting of milk, broth and meat throughout the whole period of the study. Each animal received a single dose of antibiotics intravenously in the form of ampicillin $25 \mathrm{mg} / \mathrm{kg}$ body weight (Epico pharmaceutical co., 10th of Ramadan City, Cairo, Egypt) just before the operation. All operating procedures were performed under general anesthesia and strict sterile conditions in an animal theatre. Each animal was generally anaesthetized via intravenous injection of thiopentone sodium 5\% (Egyptian international pharmaceutical industries company (E.I.P.co), the dose of which was calculated on the basis of $30 \mathrm{mg} / \mathrm{kg}$ body weight.

With the dogs under general anesthesia, a $5 \mathrm{~cm}$ gingival incision was performed on the buccal side in the premolar region on both sides of the dogs mandible and the mucoperiosteal flap was elevated, an Osseous defect of 10 $\mathrm{mm}$ depth and $10 \mathrm{~mm}$ width was created on both sides of the dogs mandible by the aid of a trephine bur on electric motor under copious saline irrigation (fig.1).

Group I: The right side of the body of the mandible was packed with PTG (fig.2a).

Group II: The left side of the body of the mandible was packed with Nanobone ${ }^{\circledR}$ (fig.2b) 3/0 chromic cat gut was used to suture the flap.

Post-operatively, the animals were transferred to a clean cage to be kept under observation to assess the presence or absence of any infection, wound dehiscence or graft rejection, they were kept on soft diet consisting of bread, milk and broth during the first four weeks postoperatively, the dogs received intra-muscular injection in the form of $(25-50 \mathrm{mg} / \mathrm{kg} / \mathrm{dog}$ of ampicillin) every 24 hours for 5 days post-operatively, the dogs received the same course of medication; anti-inflammatory and analgesic in the form of diclofenac potassium 25mg/day (Cataflam, Novartis pharma, cairo, Egypt) twice daily for 3 days.

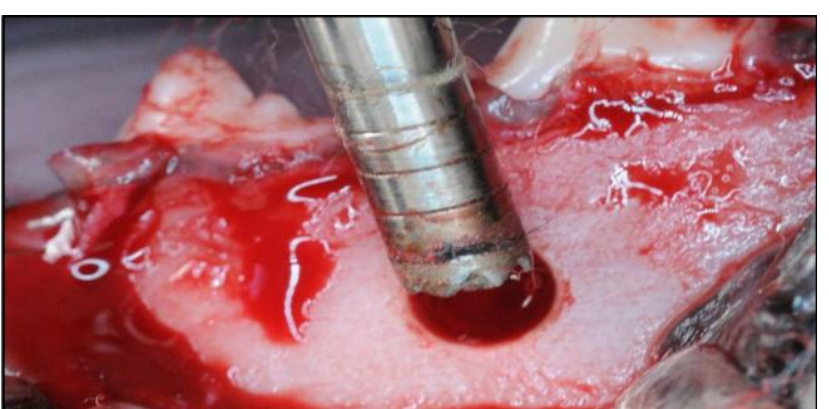

Fig. 1: A photograph showing an osseous defect of 10mm width and $10 \mathrm{~mm}$ depth created in the mandibular premolar area.

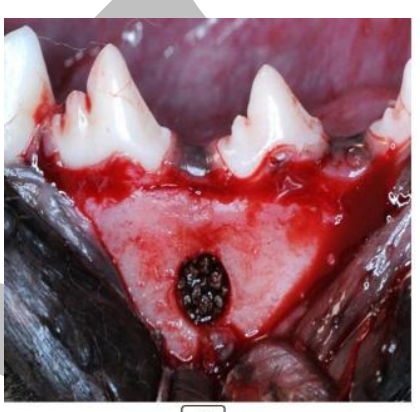

A

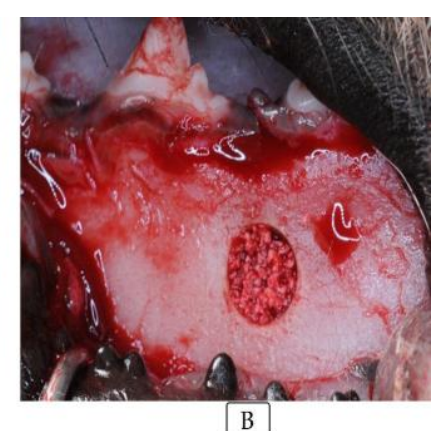

B
Fig2: (a) A photograph showing grafting of the bone defect of the right side of the mandible with PTG.

(b) A photograph showing grafting of the bone defect of the left side of the mandible with NanoBone ${ }^{\circledR}$.

The animals were inspected clinically on the first few post-operative days and then weekly till the end of follow up period for the presence or absence of infection or any arising complications, also the general condition and healing of the surgical sites were inspected. The animals were sacrificed by an intravenous overdose of thiopentone sodium (three at the 3th week, three at the 6th week and four at the 12thweek). The mandibles were extirpated and hemisected through the symphysis. The specimens were then prepared for histological examination. After the slides had been stained by H\&E stains, the histomorphometric analysis was performed.

The histomorphometric analysis is a quantitative analysis that helps histological assessment of bone phenotypes and allows comparison between groups even when the difference is not obvious. In this analysis, from each specimen obtained from both groups (I and II), five slides of the prepared $\mathrm{H} \& \mathrm{E}$ stained histological section were used. The slides were examined in an optical microscope (Aristoplan-Leitz ${ }^{\circledR}$, Leica, Wetzlar, Hesse, Germany) at 100x magnification power, through a camera (Axio Cam MRc5®, Zeiss, Santo Amaro, SP, Brazil) connected to a computer. Using Leica Qwin 500 image analyzer computer software, the images were converted into digital files, standardizing the height, width and number of pixels per inch. The amount of bone formed with each group at 3,6 and 12 weeks intervals was quantified in pixels. The mean of these values was assigned to each slide, and the value was used for statistical analysis.

The statistical analysis was performed to evaluate the 
bone volume formed with PTG and Nanobone ${ }^{\circledR}$ on intervals of 3, 6 and 12 weeks.

\section{Statistical analysis of the data}

Data were fed to the computer and analyzed using IBM SPSS software package version 20.0. Quantitative data were described using Range (minimum and maximum), mean, standard deviation and median. The distributions of quantitative variables were tested for normality using Kolmogorov-Smirnov test, Shapiro-Wilk test and D'Agstino test, also Histogram and QQ plot were used for vision test. The data were abnormally distributed so, non-parametric tests were used. For abnormally distributed data, comparison between two independent populations were done using Mann Whitney test. Significance of the obtained results was judged at the $5 \%$ level.

\section{RESULTS}

\section{Macroscopic results}

All animals tolerated the surgical procedure without complications, and they started to eat on the first postoperative day and exhibited a normal pattern of activity. Healing was uneventful without any signs of infection or wound dehiscence.

All blocks obtained from both group I and group II at 3, 6 and 12 weeks were prepared for microscopic and histomorphometric evaluation.

Microscopic results: Hematoxylin and Eosin stain

On the third postoperative week

\section{Group I (PTG group)}

Complete filling of the defect areas by dense collagen fibers with high vascularity surrounding the PTG with fibroblasts in between and old bone bordering the defect areas. No inflammatory reaction was detected. The mean bone volume value with PTG was $773.4 \pm 499.4 \mathrm{~mm} 3$ on the $3 \mathrm{rd}$ week (Table 1, Fig. 3a).
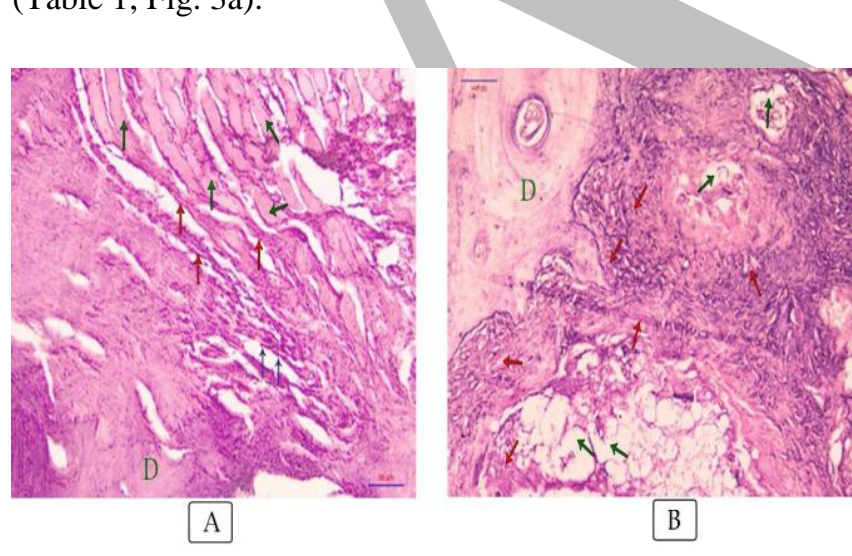

Fig. 3: (a) LMs after 3 weeks showing dense collagen fibers (red arrows) with many vascular spaces in between surrounding the homogenous Tigran substance filling the defect area (green arrows). (H\&E stain x100)

(b) LMs after 3 weeks showing Nanobone ${ }^{\circledR}$ filling the defect areas (red arrows) with granulation tissue surrounding the material. (H\&E stain x100)
Table 1: Comparison between PTG and Nanobone regarding bone volume after 3 weeks.

\begin{tabular}{|c|c|c|c|c|c|}
\hline Duration & $\begin{array}{c}\text { PTG } \\
(\mathbf{n}=\mathbf{1 0})\end{array}$ & $\begin{array}{c}\text { Nanobone } \\
(\mathbf{n}=\mathbf{1 0})\end{array}$ & $\mathbf{Z}$ & & $\mathbf{p}$ \\
\hline $\begin{array}{c}\text { After 3 weeks } \\
\left(\mathbf{m m}^{3}\right)\left(\mathbf{x 1 0} \mathbf{3}^{\mathbf{3}}\right)\end{array}$ & & & & & \\
Min. - Max. & $79.5-1239.4$ & $120.8-1008.5$ & & & \\
Mean \pm SD & $773.4 \pm 499.4$ & $525.5 \pm 332.1$ & 0.361 & & \multirow{2}{*}{0.393} \\
Median & $961.7 \mathrm{~mm}^{3}$ & $391.9 \mathrm{~mm}^{3}$ & & & \\
\hline
\end{tabular}

Z: Z for Mann Whitney test

*: Statistically not significant at $\mathrm{p}>0.05$

\section{Group II (Nanobone ${ }^{\circledR}$ group)}

Nanobone ${ }^{\circledR}$ filling the defect area with granulation tissue in between except for some areas of resorption of the graft material, as the inorganic components of Nanobone ${ }^{\circledR}$ were removed by decalcification process so it appeared as empty spaces. There is a few amount of fibrovascular tissue and old bone found at the periphery of the defect. No inflammatory cells were detected. The mean bone volume value with Nanobone ${ }^{\circledR}$ was $525.5 \pm 332.1 \mathrm{~mm} 3$ on the $3 \mathrm{rd}$ week. (Table 1, Fig. 3b)

\section{On the sixth postoperative week Group I (PTG group)}

The defect areas showed deposition of newly calcified bone spicules over the PTG surrounding irregular areas with remnants of homogenous PTG, osteoid ground substance of bone and slight fibers in between. The mean bone volume value with PTG was $10125.3 \pm 19287.3 \mathrm{~mm} 3$ on the 6 th week. (Table 2, Fig. 4a)

\section{Group II (Nanobone® group)}

Although, Nanobone ${ }^{\circledR}$ still occupying parts of the defect areas, newly formed bony specules were seen occupying the resorbed graft areas. Nanobone ${ }^{\circledR}$ was separated from the old bone surface with some granulation tissue within the space. The active osteoblasts were observed rimming the new bone and connected to old bone. The mean bone volume value with Nanobone ${ }^{\circledR}$ was $287.4 \pm 322.5 \mathrm{~mm} 3$ on the 6 th week. (Table 2, Fig .4b)

Table 2: Comparison between PTG and Nanobone regarding bone volume after 6 weeks.

\begin{tabular}{|c|c|c|c|c|}
\hline Duration & $\begin{array}{l}\text { PTG } \\
(n=10)\end{array}$ & $\begin{array}{l}\text { Nanobone }^{(} \\
(\mathrm{n}=10)\end{array}$ & Z & p \\
\hline $\begin{array}{l}\text { After } 6 \text { weeks } \\
\left(\mathrm{mm}^{3}\right)\left(\mathrm{x} 10^{3}\right)\end{array}$ & & & & \\
\hline Min. - Max. & $253.0-46689.3$ & $70.2-890.4$ & & \\
\hline Mean \pm SD & $10125.3 \pm 19287.3$ & $287.4 \pm 322.5$ & $2.883^{*}$ & $0.004^{*}$ \\
\hline Median & $763.7 \mathrm{~mm}^{3}$ & $190.3 \mathrm{~mm}^{3}$ & & \\
\hline
\end{tabular}

Z: Z for Mann Whitney test

*: Statistically not significant at $\mathrm{p}>0.05$ 

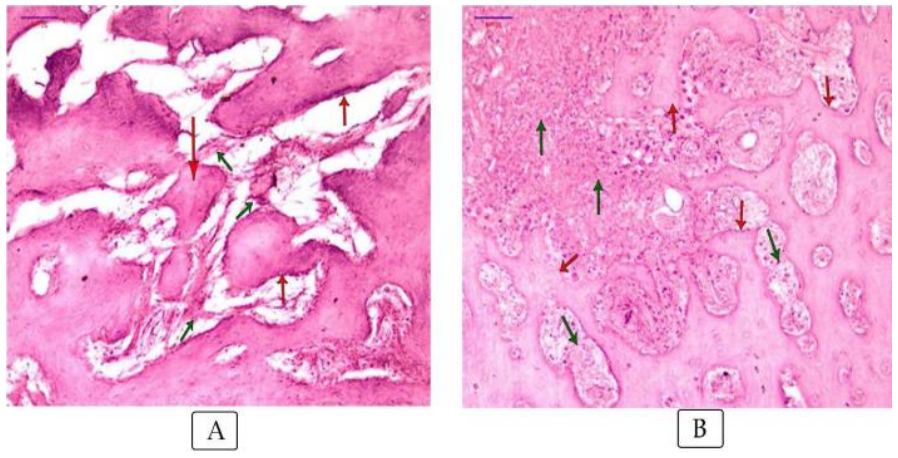

Fig. 4: (a) LMs after 6 weeks showing the defect areas almost filled with calcified bone spicules formed over the Tigran granules (red arrows) with areas in between containing slight fibers and remnants of homogenous tigran granules and osteoid ground substance. (green arrows). (H\&E stain $\mathrm{x} 100)$

(b) LMs after 6 weeks showing the newly formed bone spicules replacing areas of resorbed Nanobone ${ }^{\circledR}$ and connected to the old bone surface (red arrows) with remnants of the graft in its way to resorption and still filling the defect areas with granulation tissue (green arrows). (H\&E stain x100)

\section{On the twelfth postoperative week} Group I (PTG group)

Complete filling of the defect areas with newly formed thick bone and fusion with the old bone trabeculae. Haversian systems and osteocytes were seen with clear lines of demarcation between old and new bone. There were very small areas in its way of calcification. The mean bone volume value with PTG was $2676.0 \pm 1388.2 \mathrm{~mm} 3$ on the 12th week. (Table3, Fig. 5a)

\section{Group II (Nanobone® group)}

The defect areas were filled with newly formed bone spicules replacing areas of resorption of the graft material and connected to the old bone. There were areas of unresorbed Nanobone $®$ still well demarcated from the newly formed bone and surrounded by fibrous tissue. The mean bone volume value with Nanobone® was $1976.8 \pm$ $1568.1 \mathrm{~mm} 3$ on the 12 th week. (Table 3, Fig. 5b)

Table 3: Comparison between PTG and Nanobone regarding bone volume after 12 weeks

\begin{tabular}{|c|c|c|c|c|}
\hline \hline Duration & $\begin{array}{c}\text { Tigran } \\
(\mathbf{n}=\mathbf{1 0})\end{array}$ & $\begin{array}{c}\text { Nanobone } \\
(\mathbf{n}=\mathbf{1 0})\end{array}$ & $\mathbf{Z}$ & $\mathbf{p}$ \\
\hline $\begin{array}{c}\text { After 12 weeks } \\
\left(\mathbf{m m}^{3}\right)\left(\mathbf{x 1 0} \mathbf{0}^{3}\right)\end{array}$ & & & & \\
Min. - Max. & $618.4-4410.5$ & $100.7-3924.7$ & & \\
Mean \pm SD & $2676.0 \pm 1388.2$ & $1976.8 \pm 1568.1$ & $3.187^{*}$ & $0.001^{*}$ \\
Median & $2463.1 \mathrm{~mm}^{3}$ & $1575.6 \mathrm{~mm}^{3}$ & & \\
\hline \hline
\end{tabular}

Z: Z for Mann Whitney test

*: Statistically not significant at $\mathrm{p}>0.05$
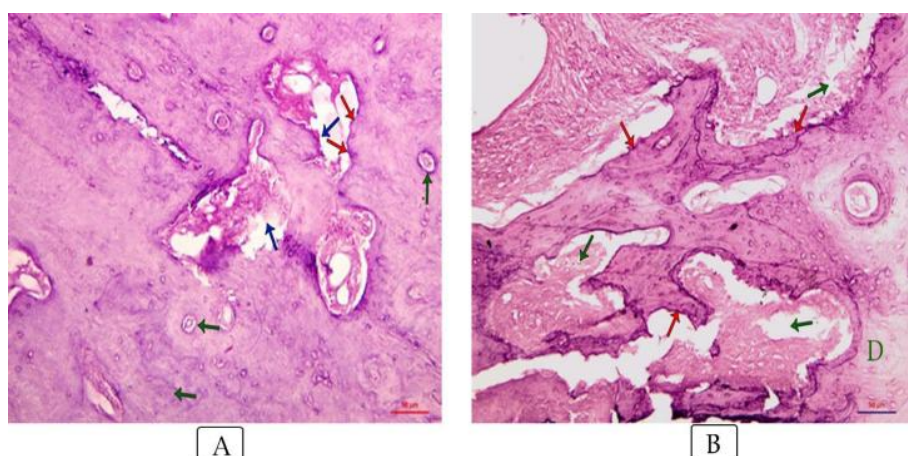

Fig. 5: (a) LMs after 12 weeks showing Complete filling of the defect area with thick, new and well calcified bone. (H\&E stain $\mathrm{x} 100$ )

(b) LMs after 12 weeks showing new bone specules filling the defect areas replacing the resorbed Nanobone ${ }^{\circledR}$ (red arrows) and connected to the old bone (D). (H\&E stain $\mathrm{x} 100)$

The mean bone volume value on the 3rd postoperative week showed no statistically significant difference when comparing PTG with Nanobone ${ }^{\circledR}$ in osseous defects regeneration $(\mathrm{p}=0.393)$ (Table 1$)$. While, the mean bone volume value on the 6 th postoperative week showed a statistically significant difference when comparing PTG with Nanobone $\AA$ in osseous defects regeneration $(p=0.004)$ (Table 2). Also, the mean bone volume value showed statistically significant difference on the12th postoperative week when comparing PTG with Nanobone ${ }^{\circledR}$ in osseous defects regeneration $(\mathrm{p}=0.001)$ (Table 3, fig.6).

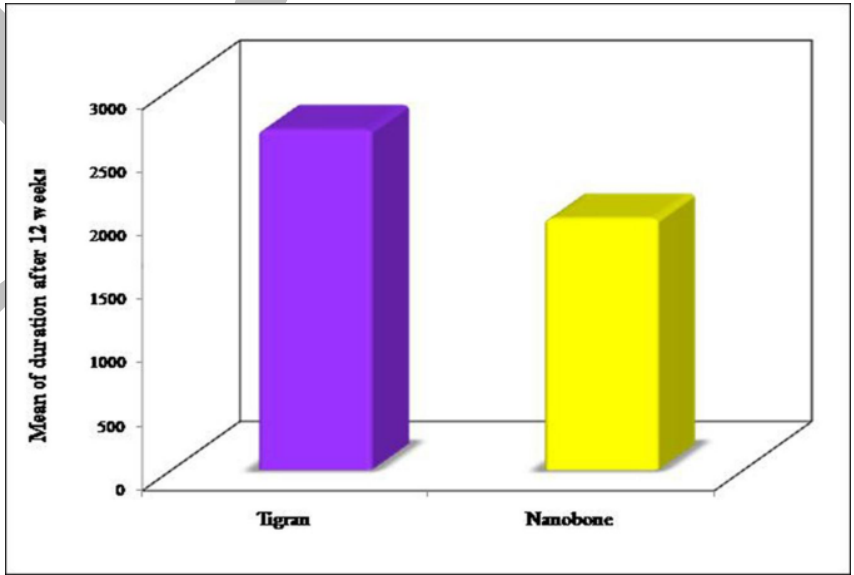

Fig. 6: Comparison between PTG and Nanobone ${ }^{\circledR}$ regarding total bone volume after 12 weeks.

\section{DISCUSSION}

Reconstruction of maxillofacial continuity defects has always been a challenge for scientists and surgeons over the years. The main goal of the reconstruction of the maxillofacial region is to restore facial form, function, full rehabilitation of occlusion and articulation (14).

The present study was conducted to compare the effect of PTG and Nanobone ${ }^{\circledR}$ on bone healing of surgically created osseous defects in dogs. The dogs were divided equally into two groups; 
Group I: A surgical defect was created in the right side of the body of the mandible and was grafted with PTG.

Group II: A surgical defect was created in the left side of the body of the mandible and was grafted with Nanobone®.

In this study, the experimental animals of choice were the Dogs due to several advantages including: being less expensive to maintain, cost effective to feed and they show patterns of bone accretion and peak bone mass profiles similar to those of human as well as true skeletal maturity (15).

The present study revealed that PTG can be considered as an appropriate bone substitute material, and it can promote bone regeneration in bone defects due to its osteoconductive properties, these results agreed with Wohlfahrt et al in 2010 (16) who stated that significantly more bone was formed in PTG grafted defects compared to those left empty. The new bone grew both through the porosities of the granules and onto the implant surfaces.

PTG belongs to a class of material that may be preferable for filling cavities because it serves as a nonresorbable scaffold that promotes a three-dimensional matrix, which can stabilize and maintain the shape of the filled area. This agreed with Marei in 2010 (17) where PTG were packed around the implant in the coronal gap between the fixture and socket wall; PTG showed good stabilization of the implant and preferable osseointegration between bone and the implant surface without being resorbed.

The histomorphometric analysis in the present study revealed that the bone volume value in the osseous defects filled with PTG was higher than those occupied with Nanobone ${ }^{\circledR}$ but no statistically significant difference could be detected between the two groups. This agreed with Wälivaara and Abrahamsson in 2013 (18) where no statistically significant difference could be detected between autogenous bone or one of the bone graft substitutes, when they were used to fill osseous defects in dogs following apicectomy of mandibular premolars. This non -significant difference might be explained by sample size limitation.

The present study proved that PTG can be used in small defects without membrane. This disagreed with Ruiz RF et al. in 2014 (19) who found that the PTG particles must be covered by a membrane, especially when grafting larger defects, to control particle dislocation, promote clot stabilization and separate the PTG graft from undesired soft tissue cells.

Macroscopically, no signs of inflammation and complete healing of the surgical sites was observed in all dogs of both groups. These findings agree with those of Gholami in 2010 (20) who reported the application of PTG does not interfere with the initial healing of the surgical wound. Bone marrow around PTG was fatty vascular but in some locations where grafted material (BIO-OSS and BIOGEN) were used, the bone marrow was fibrovascular which provides evidence that the bone formation remodeling process in the samples containing PTG was developing correctly.

There were no signs of infection, abnormal reaction, wound dehiscence or extrusion of the material in any of the dogs. This disagreed with GabAllah in 2014 (21) where gingival inflammation, apical migration of attachment epithelium and destruction of the periodontuim were detected. The signs of complete periodontium regeneration were not clearly seen when Nanobone ${ }^{\circledR}$ was tested in healing of periodontal defects in dogs in comparison with autogenous grafts and control groups.

In two studies performed by Gotz et al (22) in 2010 and Harms et al in 2012 (23), they reported a high osteoconductivity of Nanobone®. The presence of silicate ions appears to promote the process of bone formation and remodeling at the bone-Hydroxyapatite interface. In contrast to what was observed with other HA-based bone substitute materials, the rapid osseointegration of Nanobone ${ }^{\circledR}$ seemed to prevent its complete degradation. The Nanobone $\AA$ particles were completely and firmly embedded within newly formed bone without a detectable fibrous interface and with no indication of an adverse host reaction to the material. This agreed with the present study that showed varying amounts of newly formed bone found through the specimens. Well-mineralized regenerated bone with lamellar parallel-fibred structure and Haversian systems surrounded the residual NanoBone ${ }^{\circledR}$ particles. These results also were in accordance with Canullo L (24) in 2009 who concluded that NanoBone ${ }^{\circledR}$ showed good histological outcomes for augmenting maxillary sinus floor with critical bone volume. There was evidence of new bone formed at (3, 6 and 12) weeks in defects filled with NanoBone ${ }^{\circ}$. The area under the graft gradually filled with new bone adjacent to peripheral defective area with bundles of connective tissue fibers extending to surround the NanoBone ${ }^{\circledR}$ were observed. The bone formation became apparent with increasing time of implantation. This result was in accordance with Alaa, Jaber, Kadhim and Al-Soudani (25) in 2012 where the amount of new bone formed in NanoBone $\AA$ filled defects was much more than that formed in controls when it was used in healing of experimentally induced frontal bone defects in rabbits.

The present study revealed complete healing of the defects in all dogs with new bone formation without the need to use a membrane. This result was in agreement with EL Dibany and Shoukry (26) in 2014 where the combined use of Nanobone ${ }^{\circledR}$ and PRF for bone regeneration following the enucleation of large mandibular odontogenic cysts induced accelerated bone healing and improved the quality and quantity of regenerated bone also without using a membrane.

Histologically, the results of the present study were: Group I; the defect areas showed signs of complete fusion and healing of PTG with formation of bone trabeculae and immature Haversian system. Complete filling of the defect area with thick, new well calcified bone and lines of demarcation with old bone, numerous old osteons and osteocytes. Woven bone is a weak structure and does not have well-organized tissues (27) and it is the first bone tissue that is formed in the bone regeneration process (28).

Regarding Group II, bone formation was seen in direct contact with surface of NanoBone ${ }^{\circledR}$ granules, also there was 
obviously fibrous connective tissue embedded in the calcified matrix. Mature connective tissue form the inter granule matrix $(29,30)$.

\section{CONCLUSIONS}

Both PTG and NanoBone ${ }^{\circledR}$ are effective in osseous defect regeneration by forming new bone. Regarding the mean bone volume value, there was a statistically non-significant relation between PTG and NanoBone ${ }^{\circledR}$ groups on the 3rd week, while the relation is statistically significant between them at the 6 th and 12 th week.

The bone volume formed with PTG was more than that formed with NanoBone ${ }^{\circledR}$ throughout the follow up period.

\section{CONFLICT OF INTEREST}

The authors declare that they have no conflicts of interest. The guidelines for the care and use of experimental animals according to the institution in which the work was done were followed.

\section{REFERENCES}

1. Palti A, Hoch T. A concept for the treatment of various dental bone defects. Implant Dent. 2002;11:73-7.

2. Schöpf C, Daiber W, Tadic D. Tutoplast processed allografts and xenografts in 3D block technique from image diagnostics to block graft bone regeneration. RC Libri Milano. 2005;5:54-75.

3. Platzer S, Wildburger A, Lorenzoni M, Jakse $N$, Riedl R, Weiglein A, et al. Human cadaver study evaluating a new measurement technique for graft volumes after sinus floor elevation. Clin Impl Dent Rel Res. 2012;16:212-22.

4. Silber JS, Anderson DG, Daffner SD, Brislin BT. Donor site morbidity after anterior iliac crest bone harvest for single level anterior cervical discectomy and fusion. Spine. 2003;28:134-9.

5. Ronolad L, Ellingston JE. The use of a coin shaped for direct in situ measurement of attachment strength for osseointegrating biomaterial surfaces. Bio. 2002;23:2201-9.

6. Schnettler R, Dingeldein E. Inorganic bone substitutes. Tissue Engineering and Biodegradable Equivalents: Scientific and Clinical Applications. Vol 25. New York: Marcell Dekker; 2002.401-32.

7. Schwarz F, Bieling K, Latz T, Nuesry E, Becker J. Healing of intrabony periimplantitis defects following application of a nanocrystalline hydroxyapatite (Ostims ${ }^{\circledR}$ ) or a bovine-derived xenograft (Bio-Oss) in combination with a collagen membrane (Bio-Gide). A case series. J Clin Perio. 2006;33:491-9.

8. Gerike $\mathrm{W}$, Bienengräber $\mathrm{V}$, Henkel $\mathrm{KO}$, Bayerlein $\mathrm{T}$, Proff P, Gerber T, et al. The manufacture of synthetic non-sintered and degradable bone grafting substitutes.
Folia Morphol (Warsz). 2006;65:54-5.

9. Watson JT. Treatment of tibial fractures with bone loss. Tech Ortho. 1996;11:132-43.

10. Araujo MG, Lindhe J. Dimensional ridge alterations following tooth extraction. An experimental study in the dog. J Clin Periodontol. 2005;32:212-8.

11. Schmidlin PR, Jung RE, Schug J. Prevention of alveolar ridge resorption after tooth extraction--a review. Schweiz Monatsschr Zahnmed. 2004; 114: 328-36.

12. Buch RS, Wagner W, Reichert TE. Alveolar-ridgepreservation. Impl. 2005;21:30-7.

13. Hämmerle $\mathrm{CH}$, Araújo $\mathrm{MG}$, Simion M. Osteology Consens group 2011. Evidence-based knowledge on the biology and treatment of extraction sockets. Clin Oral Implant Res. 2012;23:80-2.

14. Alfotawi R, Ayoub A. Reconstruction of maxillofacial bone defects: Contemporary methods and future techniques. Am J Adv Med Sci. 2014; 1: 18-27.

15. Betancourt N, García L, Alejandro T. Propolis in dogs: Clinical experiences and perspectives (A Brief Review). J vet med. 2015; 5: 11-17.

16. Wohlfahrt JC, Monjo M, Rønold HJ, Aass AM, Ellingsen JE, Lyngstadaas SP. Porous titanium granules promote bone healing and growth in rabbit tibia peri implant osseous defects. Clin Oral Implants Res. 2010;21:165-73.

17. Marei MG. Clinical and radiographic evaluation of porous titanium granules around immediate dental implants. M.Sc. Thesis. Faculty of Dentistry, Alexandria University. 2010.

18. Wälivaara DA, Abrahamsson P. Evaluation of 4 different bone graft substitutes and autogenous bone grafting in root-end resection osteotomies after retrograde root-filling with Intermediate Restorative Material (IRM): An experimental study in dogs. Open Journal of Stomatology. 2013;3:203-8.

19. Delgado-Ruiz RA, Calvo-Guirado JL, Abboud M, Ramirez-Fernández MP, Maté-Sánchez JE, Negri B, et al. Porous titanium granules in critical size defects of rabbit tibia with or without membranes. Int J Oral Sci. 2014;6:105-10.

20. Gholami GA, Techranchi M, Kadkhoda M. Histologic and histomorphometric evaluation of bone substitutes in experimental defects. Res J Bio Sci. 2010;5:465-9.

21. GabAllah OM, El Tokhey HM, Abd-Elmotelb MA, ElGuindy HM, Saleh RG. Nanotechnology and its Role in the Treatment of Induced Periodontitis (Experimental Study). J Am Sci. 2014;10: 179-95.

22. Geotz W, Lenz S, Reichert C, Henkel KO, Bienengreaber V, Pernicka L, et al. A preliminary study in osteoinduction by a nanocrystalline 
hydroxyapatite in the mini pigs. Folia Histochem Cytobiol. 2010;48:589-96.

23. Harms C, Helms K, Taschner T, Stratos I, Ignatius A, Gerber $\mathrm{T}$, et al. Osteogenic capacity of nanocrystalline bone cement in a weight bearing defect at the bovine tibial metaphysis. Int J Nanomed. 2012;7:2883-9.

24. Canullo L, Vozza I, Caricato F, Dellavia C. Maxillary sinus floor augmentation using a nanocrystalline hydroxyapatite silica gel. A prospective studyHistological results after 3 months of healing Implants, Int Magazine of Oral Impl. 2009;2:24-7.

25. Alaa SJ, Kadhim A, Al-Soudani B. Histopathological evaluation of bone healing using Nanobone ${ }^{\circledR}$ in experimentally induced frontal bone defects of rabbits. J Bagh College Dent. 2012;24:40-5.

26. Eldibany RM, Shokry MM. The effect of Nanobone ${ }^{\circledR}$ in combination with platelet rich fibrin on bone regeneration following enucleation of large mandibular cysts. Tanta Dental Journal. 2014;11:100-8.

27. Roberts W. Bone physiology, metabolism, and biomechanics in orthodontic practice; orthodontics: Current principles and techniques. Vol 4. Ortho: Current Principles and Techniques; 2005. 221-92.

28. Hallman M, Lundgren S, Sennerby L. Histologic analysis of clinical biopsies taken 6 months and 3 years after maxillary sinus floor augmentation with $80 \%$ bovine hydroxyapatite and $20 \%$ autogenous bone mixed with fibrin glue. Clin Imp Dent Relat Res. 2001;3:8796.

29. Abshagen K, Schrodi I, Gerber T, Vollmar B. In vivo analysis of biocompatibility and vascularization of the synthetic bone grafting substitute NanoBone®. J Biomed Mater Res A. 2009;91:557-66.

30. Fathi MH, Mortazavi V, Roohani SI. Bioactivity evaluation of synthetic nanocrystalline hydroxyapatite. Dent Res J (Isfahan) 2008; 5: 81-7.

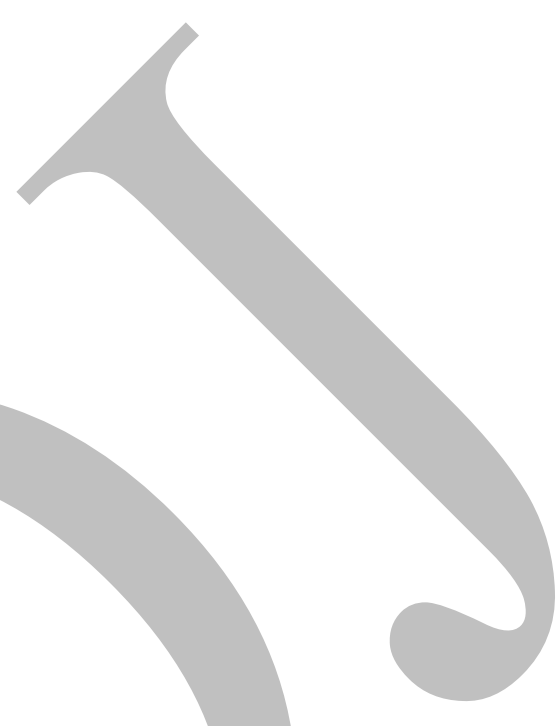

.

